Research Perspective

\title{
A state of stochastic cancer stemness through the CDK1-SOX2 axis
}

\author{
Dinoop Ravindran Menon ${ }^{1}$ and Mayumi Fujita ${ }^{1,2,3}$ \\ ${ }^{1}$ Department of Dermatology, University of Colorado Denver, Aurora, CO, USA \\ 2 Denver VA Medical Center, Denver, CO, USA \\ ${ }^{3}$ Department of Immunology and Microbiology, University of Colorado Denver, Aurora, CO, USA \\ Correspondence to: Mayumi Fujita, email: mayumi.fujita@ucdenver.edu \\ Keywords: cancer stemness; melanoma; immune evasion; CDK1; SOX2
}

Received: January 25, $2019 \quad$ Accepted: February 03, $2019 \quad$ Published: April 05, 2019

Copyright: Menon et al. This is an open-access article distributed under the terms of the Creative Commons Attribution License 3.0 (CC BY 3.0), which permits unrestricted use, distribution, and reproduction in any medium, provided the original author and source are credited.

\section{ABSTRACT}

The concept of cancer stemness has undergone a paradigm shift during the last decade where there is wider acceptance of the idea that stemness in cancer is a more dynamic and plastic phenomenon than previously thought. However, we have yet to understand the mechanisms on how this stochastic plasticity arises and is maintained. Recently, we have shown that CDK1 plays a critical role in stochastic stemness and tumor initiation potential through regulating SOX2 phosphorylation in multiple cancer types. The phosphorylation of SOX2 affects its nuclear localization, thereby determining the transcriptional fate of its downstream targets. We have also validated the significance of these findings using clinical samples by demonstrating that CDK1 $1^{\text {high }}$ tumor samples displayed upregulation of MYC target genes, which were reported to overlap with SOX2 targets. In the current article, we further discuss the possibility of a closed, feed-forward loop between SOX2 and CDK1 through a long non-coding RNA, CCAT1, which would explain the sustained activation of this loop. Despite the extensive investigation of the cancer stemness as a cause of drug resistance, its role in immune evasion still requires further understanding, and hence, in this article, we further discuss the possibility of this CDK1-SOX2 axis contributing to immune resistance through modulating cell-to-cell interaction directly or indirectly in the tumor microenvironment.

Cancer stemness is a concept that has evolved with our understanding of the nature of cancer cells. In certain cancer types such as colon cancer and squamous cell carcinoma, lineage-tracing studies using mouse models have pointed to a hierarchical model of cancer development where epithelial stem cells have been identified as the cause of tumor initiation. However, cancer cells exhibit an exorbitant plasticity in their phenotypes after the transition into a cancerous state, and even adult stem cells can exist in a state of constant flux or nonhierarchical plasticity in the tissue microenvironment, all of which implicate a shift from a hierarchical rigid model of cancer stem cells to a non-hierarchical or phenotypically plastic model [1].

Despite numerous studies investigating the phenotypic markers and functional consequences of the plastic state of cancer cells, there is a dearth of information available on the molecular mechanisms regulating this plasticity. Our recent study sheds light on this field by elucidating a novel mechanism of CDK1 contributing to cancer stemness. We have demonstrated an upregulation of CDK1 in a subpopulation of melanoma and colon cancer cells with high MHC I expression that displayed high tumor initiating potential [2]. The expression of MHC I in these cells was driven by CDK1 through the NF-kB pathway and resulted in phenotypic plasticity, indicating a non-hierarchical stochastic switching between stem-like and non-stem-like states. It needs to be noted that tumor initiating potential is different from tumor growth rate: the former represents an ability of cancer cells to initiate or form tumors whereas the latter is associated with the speed of tumor growth. Portrayed by this difference, modulating 
CDK1 activity altered tumor initiating potential without affecting cell proliferation in 2D assays. These findings illustrate a CDK1-mediated plasticity and stem-like phenotype in cancer cells.

We have also delineated an indispensable role for the stem cell transcription factor SOX2 in CDK1mediated stemness and tumorigenesis by demonstrating the interaction of CDK1 with SOX2 in cancer cells. SOX2 is known to be instrumental in tumorigenesis in multiple cancer types [3, 4]; however, its role in melanoma has been controversial [2, 5-7]. Whereas some reports, including ours, revealed the importance of SOX2 in tumor initiation [2] [5], others demonstrated an opposite trend using mouse melanoma models $[6,7]$. Functional consequences of SOX2 depend on its expression, posttranslational modification, subcellular localization and interaction with other transcription factors, which might explain the discrepancy in the role of SOX2 reported in various studies. By dissecting transcriptional activities and nuclear localization of SOX2, we have uncovered a vital role of CDK1 in governing the transcriptional activity of SOX2 through its phosphorylation at S249-S250-S251, the sites required for nuclear translocation of SOX2 [2].

Furthermore, we have validated the clinical significance of our findings by unveiling the involvement of CDK1 in MYC target genes, mTOR signaling and DNA repair pathways in patient tumors from melanoma, colon and pancreatic cancer. Among these signatures, the upregulation of MYC target genes is of particular importance because MYC can bind to up to $85 \%$ of the same promoters as SOX2, amplifying its downstream targets including various CDKs [8]. A previous report has shown that CDK1 is indispensable for survival of cancer cells overexpressing MYC [9]. Therefore, we speculated crosstalk between CDK1 and SOX2/MYC in melanoma, and silenced SOX2 in human melanoma cells. Consistent with our hypothesis, we found downregulation of CDK1 after SOX2 knockdown in these cells (Figure 1A and 1B). Recent reports have demonstrated that both SOX2 [10] and MYC [11] activate colon cancer-associated transcript 1 (CCAT1), a long non-coding RNA. CCAT1 upregulates CDK1 in liver cancer cells by binding to and sponging miR-490-3p, a micro RNA known to downregulate CDK1 expression [12]. Together with our previous study showing the regulation of SOX2 by $\mathrm{CDK} 1$, these data indicate the presence of a closed, feed-forward loop in the CDK1SOX2 axis in melanoma, as depicted in Figure 1C.

Another emerging field of interest is the role of cancer stemness in immune evasion. Immunotherapies have shown to be effective in many cancer types including melanoma; however, only a minority of patients exhibit a durable and sustained response to immunotherapies [13]. Accumulating evidence suggests an important role for SOX2 in cancer immune evasion $[14,15]$. Fox example, Dickkopf-related protein 1 (DKK1), induced by SOX2, positively regulates myeloid-derived suppressor cells in the tumor microenvironment [14] and provides metastatic latency and immune evasion in lung cancer by protecting cells from NK cells [15]. NANOG, an embryonic stem cell-related gene and another target of SOX2 [2], is also shown to induce resistance to lysis by cytotoxic $\mathrm{T}$ cells in cervical cancer [16].

Altogether, our study provides a mechanistic perspective on cancer progression through CDK1-SOX2mediated cancer stemness and immune evasion of tumor cells. Hence, targeting the CDK1-SOX2 axis would
A

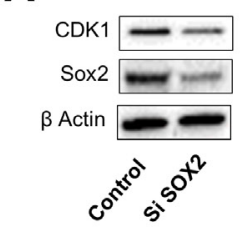

B

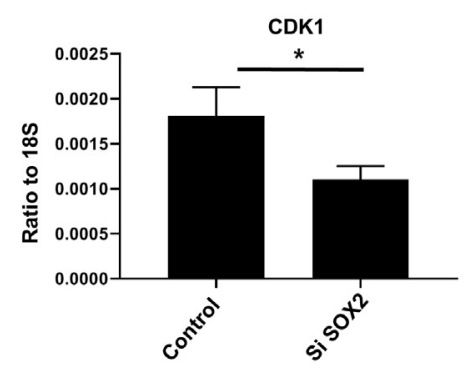

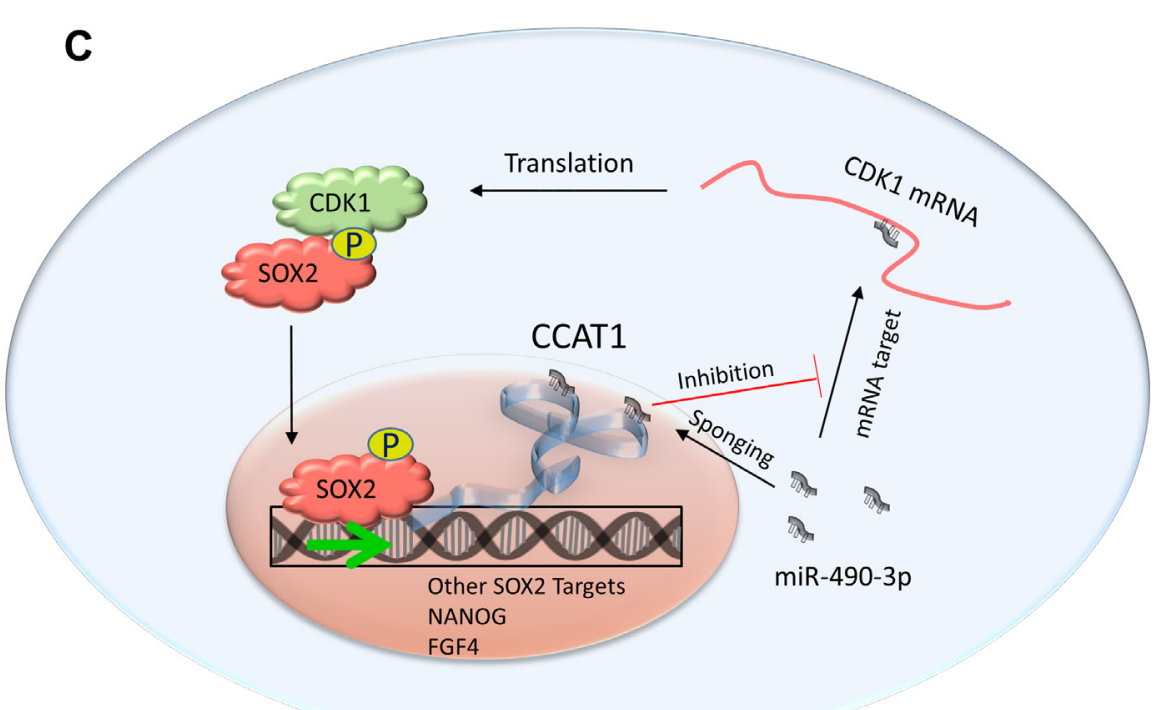

Figure 1: SOX2 regulates CDK1 through a feed-forward loop. A. Sox2 knockdown by siRNA (left) or CRISPR (right) in A375 cells downregulates CDK1 protein expression. B. SOX2 siRNA knockdown in A375 cells downregulates CDK1 mRNA expression. C. Graphical representation of a possible feed-forward loop regulating CDK1 and SOX2. 
hold immense promise in future cancer therapeutics, and warrants further investigation.

\section{ACKNOWLEDGMENTS}

We thank Ms. Joanne Domenico (Dermatology, UCD) for editing the manuscript. This work was supported in part by grants from NIH/NCI R01CA197919 (to M. Fujita), Veterans Affairs Merit Review Award 5I01BX001228 (to M. Fujita) and Cancer League of Colorado (to M. Fujita).

\section{CONFLICTS OF INTEREST}

The authors declare no conflicts of interest.

\section{REFERENCES}

1. Batlle E, Clevers H. Cancer stem cells revisited. Nat Med. 2017; 23:1124-34.

2. Ravindran Menon D, Luo Y, Arcaroli JJ, Liu S, KrishnanKutty LN, Osborne DG, Li Y, Samson JM, Bagby S, Tan AC, Robinson WA, Messersmith WA, Fujita M. CDK1 Interacts with Sox 2 and Promotes Tumor Initiation in Human Melanoma. Cancer Res. 2018; 78:6561-74.

3. Boumahdi S, Driessens G, Lapouge G, Rorive S, Nassar D, Le Mercier M, Delatte B, Caauwe A, Lenglez S, Nkusi E, Brohée S, Salmon I, Dubois C, et al. SOX2 controls tumour initiation and cancer stem-cell functions in squamous-cell carcinoma. Nature. 2014; 511:246-50.

4. Leis O, Eguiara A, Lopez-Arribillaga E, Alberdi MJ, Hernandez-Garcia S, Elorriaga K, Pandiella A, Rezola $\mathrm{R}$, Martin AG. Sox 2 expression in breast tumours and activation in breast cancer stem cells. Oncogene. 2012; 31:1354-65.

5. Santini R, Pietrobono S, Pandolfi S, Montagnani V, D’Amico M, Penachioni JY, Vinci MC, Borgognoni L, Stecca B. SOX2 regulates self-renewal and tumorigenicity of human melanoma-initiating cells. Oncogene. 2014; 33:4697-708.

6. Schaefer SM, Segalada C, Cheng PF, Bonalli M, Parfejevs V, Levesque MP, Dummer R, Nicolis SK, Sommer L. Sox2 is dispensable for primary melanoma and metastasis formation. Oncogene. 2017; 36:4516-24.

7. Cesarini V, Guida E, Todaro F, Di Agostino S, Tassinari V, Nicolis S, Favaro R, Caporali S, Lacal PM, Botti E, Costanzo A, Rossi P, Jannini EA, Dolci S. Sox2 is not required for melanomagenesis, melanoma growth and melanoma metastasis in vivo. Oncogene. 2017; 36: 450815.
8. Kwan KY, Shen J, Corey DP. C-MYC transcriptionally amplifies SOX2 target genes to regulate self-renewal in multipotent otic progenitor cells. Stem Cell Reports. 2015; 4:47-60.

9. Goga A, Yang D, Tward AD, Morgan DO, Bishop JM. Inhibition of CDK1 as a potential therapy for tumors overexpressing MYC. Nat Med. 2007; 13:820-27.

10. Jiang Y, Jiang YY, Xie JJ, Mayakonda A, Hazawa M, Chen L, Xiao JF, Li CQ, Huang ML, Ding LW, Sun QY, Xu L, Kanojia D, et al. Co-activation of super-enhancer-driven CCAT1 by TP63 and SOX2 promotes squamous cancer progression. Nat Commun. 2018; 9:3619.

11. He X, Tan X, Wang X, Jin H, Liu L, Ma L, Yu H, Fan Z. C-Myc-activated long noncoding RNA CCAT1 promotes colon cancer cell proliferation and invasion. Tumour Biol. $2014 ; 35: 12181-88$.

12. Dou C, Sun L, Jin X, Han M, Zhang B, Li T. Long noncoding RNA colon cancer-associated transcript 1 functions as a compe ting endogenous RNA to regulate cyclindependent kinase 1 expression by sponging miR-490-3p in hepatocellular carcinoma progression. Tumour Biol. 2017; 39:1-9.

13. Carretero-González A, Lora D, Ghanem I, Zugazagoitia J, Castellano D, Sepúlveda JM, López-Martin JA, Paz-Ares L, de Velasco G. Analysis of response rate with ANTI PD1/ PD-L1 monoclonal antibodies in advanced solid tumors: a meta-analysis of randomized clinical trials. Oncotarget. 2018; 9:8706-15.

https://doi.org/10.18632/oncotarget.24283.

14. D'Amico L, Mahajan S, Capietto AH, Yang Z, Zamani A, Ricci B, Bumpass DB, Meyer M, Su X, Wang-Gillam A, Weilbaecher K, Stewart SA, DeNardo DG, Faccio R. Dickkopf-related protein 1 (Dkk1) regulates the accumulation and function of myeloid derived suppressor cells in cancer. J Exp Med. 2016; 213:827-40.

15. Malladi S, Macalinao DG, Jin X, He L, Basnet H, Zou Y, de Stanchina E, Massagué J. Metast atic Latency and Immune Evasion through Autocrine Inhibition of WNT. Cell. 2016; $165: 45-60$.

16. Noh KH, Kim BW, Song KH, Cho H, Lee YH, Kim JH, Chung JY, Kim JH, Hewitt SM, Seong SY, Mao CP, Wu TC, Kim TW. Nanog signaling in cancer promotes stemlike phenotype and immune evasion. J Clin Invest. 2012; 122:4077-93. 